\title{
Registro de presencia y actividades de algunos mamíferos en el Desierto Chihuahuense, México
}

\author{
Cynthia Elizalde-Arellano*1, Juan Carlos López-Vidal ${ }^{1}$, Lucina Hernández ${ }^{2}$, John W. Laundré ${ }^{3}$, \\ Fernando A. Cervantes ${ }^{4}$, Fabiola M. Morales-Mejía ${ }^{5}$, Mariana Ramírez-Vargas ${ }^{1}$, Luis F. Dávila- \\ Galaviz ${ }^{1}$, Alberto González-Romero ${ }^{6}$ y María Alonso-Spilsbury ${ }^{7}$
}

Introduction: Photographic records are useful tools that had strengthen wildlife mammal studies as a noninvasive methodology providing a wide variety of information. The objective of this study is to document with images (automatic - trail cameras and manually - personal cameras) the species of mammals inhabiting the Mapimi Biospere Reserve (MBR), to highlight the morphologic characteristics that distinguish them, to record the area and vegetation type where each species was found and to determine some of their daily activities.

Methods: Between 2009 and 2014, twelve field trips were made to Mapimi. In each trip we placed six trail cameras each at five locations ( 30 cameras total) for $24 \mathrm{~h}$ during six consecutive days, with $51,840 \mathrm{~h}$ photographic effort. Two sets of six cameras were placed in grassland habitat and three in shrubland habitat. Each camera was baited with $300 \mathrm{~g}$ of alfalfa mixed with sand in a tray placed $3 \mathrm{~m}$ from the camera. Between 2011 and 2014 two additional cameras were set to monitor a natural pond on the slope of a small mountain (San Ignacio) in the area with $5,760 \mathrm{~h}$ of photographic effort. In total we had $57,600 \mathrm{~h}$ of photographic effort. Images were also obtained from manual cameras of the authors while engaged in various research projects in the area with more than 2,000 photographs. These data for some species are directly from animals captured in the locality. Their main morphologic characteristics were highlighted, specific places, type of vegetation where each species was found and some of their daily activities.

Results: A total number of five orders, 12 families, 27 genera and 31 species were recorded, representing $49 \%$ of mammals known in the Reserve. With trail cameras 1,714 photos were taken and 15 species were recorded (Table 1). The species with highest number of records were Dipodomys nelsoni $(n=610)$, D. merriami $(n=469)$ and Netoma leucodon $(n=335)$. The ones with the lowest number of photos were Ictidomys mexicanus $(n=48)$ and Sylvilagus audubonii ( $n=46$, Figure 1). Trail cameras recorded five genera where the species level could not be determined: Myotis sp., Chaetodipus sp., Peromyscus sp., Ictidomys or Xerospemorphilus. With manual cameras more than 2,000 photos were taken and thirty species were photographed, only 16 were recorded with this method (Table 1). The collared peccary (Pecari tajacu) was the single species recorded only by trailed cameras.

\footnotetext{
'ILaboratorio de Cordados Terrestres, Departamento de Zoología, Escuela Nacional de Ciencias Biológicas, Instituto Politécnico Nacional. Carpio y Plan de Ayala s/n, Casco de Santo Tomás, México D.F. 11340, México. Teléfono (5255) 5729-6000, ext. 62421, E-mail: thiadeno@hotmail.com (CEA), jclvidal@hotmail.com (JCLV), ramirez-vargasm@hotmail.com (MRV), jaguar_04@ hotmail.es (LFDG)

${ }^{2}$ Rice Creek Field Station, Department of Biological Sciences, Shineman 220 Center SUNY Oswego, Oswego, New York 13126, United States.

${ }^{3}$ James Jacinto Mountains Reserve, University of California Riverside, P.O Box 1775, Idyllwild, California 92549, United States. E-mail: john.laundre@ucr.edu (JWL)

${ }^{4}$ Departamento de Zoología, Instituto de Biología, Universidad Nacional Autónoma de México. Coyoacán, México D.F. 04510, México. E-mail: fac@ib.unam.mx (FAC)

5Laboratorio de Arqueozoología “M. en C. Ticul Álvarez Solórzano", Subdirección de Laboratorios y Apoyo Académico, Instituto Nacional de Antropología e Historia. Moneda no 16. Col. Centro, Delegación Cuauhtémoc, México D.F. 06060, México. E-mail: ardilla3@hotmail.com (FMMM)

${ }^{6}$ Red de Biología y Conservación de Vertebrados, Instituto de Ecología A. C. Carretera Antigua a Coatepec \#351. El Haya, Xalapa, Veracruz 91070, México. E-mail: alberto.gonzalez@inecol.mx (AGR)

${ }^{7}$ Laboratorio de Etología, Departamento de Producción Agrícola y Animal, Universidad Autónoma Metropolitana, Xochimilco. Calzada del Hueso 1100, Col. Villa Quietud México D.F. 04960, México. E-mail: maspilsbury@hotmail.com (MLAS) ${ }^{*}$ Corresponding author
} 
Discussion and Conclusions: Results obtained demonstrated that with trail cameras, morphological characteristics that distinguish most mammalian species can be observed clearly for most small, medium and large species. For some small species (such as Heteromyidae and Muridae) their features cannot be easily noted so their proper identity is difficult to determine. It is also important to discuss that only half of the known mammal diversity in the locality was recorded with trail cameras. Some small (such as Heteromyidae and Muridae rodents and bats), medium (as skunks) or large size species (as pumas) were not recorded with them, even though these cameras are generally considered a very effective method for mammalian inventories. As our results do not support this idea, we strongly recommend to combine direct trapping methods with trail cameras to get more complete and more realistic mammalian inventories.

The highest numbers of records obtained with trail cameras were of Dipodomys nelsoni, D. merriami and Netoma leucodon, reflecting their numerical dominance in the ecosystem. Lower number of records of Sylvilagus audubonii, squirrels, deer, peccaries and other mammals are related with their low abundance and they occur only in very specific areas. The low numbers found of Lepus californicus were contradictory with previous studies, where they were much more frequently recorded. Skunks inhabit rocky and hills parts in the Reserve, and the presence of Spilogale gracilis was exceptional and as such represents a new record of this species for the Reserve. Documentation of mammalian species through photographic images contributes to different aspects of their biology that had not been addressed before in this location. Cameras allowed updating of information of some species and helped to identify knowledge gaps that can be addressed in the future to contribute to understand the dynamics of the mammal community in the Chihuahuan Desert.

Key words: Manual cameras, new record, photographic identification, Spilogale gracilis, trail cameras.

Resumen

El presente trabajo tuvo como objetivos documentar a través de imágenes fotográficas las características morfológicas distintivas de las diferentes especies de mamíferos de la Reserva de la Biosfera de Mapimí (RBM) que permiten distinguirlas con claridad, especificar los lugares y el tipo de vegetación en los que se obtuvieron los registros y reportar algunas de sus actividades diarias. Se colocaron en total 32 cámaras trampa en áreas de matorral, pastizal y un cuerpo de agua en la ladera del Cerro San Ignacio entre los años 2009 a 2014 para un esfuerzo de muestreo total de 57,600 h, adicionalmente se obtuvieron imágenes de cámaras de uso manual. Se registraron cinco órdenes, 12 familias, 27 géneros y 31 especies que representan el $49 \%$ del total conocido para la RBM. Se eleva a 64 las especies de mamíferos reportadas para la Reserva (antes de 63) por un nuevo registro del zorrillo Spilogale gracilis. Con las cámaras trampa se registraron 15 especies y con las personales 30 de éstas, 16 especies se registraron solo por este último medio; los pecaríes de collar fueron la única especie registrada exclusivamente con cámaras trampa. Algunos mamíferos fueron identificados solo a nivel de género Myotis sp., Chaetodipus sp., Peromyscus sp., Ictidomys o Xerospemorphilus. Aún persisten diversos aspectos desconocidos sobre los mamíferos de la RBM que es recomendable investigar para contribuir a la comprensión de la dinámica del Desierto Chihuahuense.

Palabras Clave: Cámaras trampa, cámaras manuales, identificación fotográfica, nuevo registro, Spilogale gracilis. 
El registro fotográfico, tanto manual como remoto, ha incrementado su importancia como herramienta que ha fortalecido el estudio de los mamíferos silvestres debido a que es un método no invasivo y proporciona información valiosa relacionada con las características morfológicas de las especies, cuando las imágenes son de buena calidad pueden considerarse como ejemplares para colecciones científicas o museos. El uso de la fotografía remota, en particular, ha permitido estudiar con mayor detalle los diferentes aspectos de la biología de estos animales como sus patrones de actividad, algunas de sus actividades o comportamientos, la densidad de especies de tamaño mediano y grande, como las del orden carnívora que son de hábitos difíciles de investigar empleando métodos como la observación directa o el trampeo (Wemmer et al. 1996; Trolle y Kery 2005; Kelly et al. 2008; Vaughan et al. 2011). El uso de imágenes fotográficas para el estudio de los mamíferos permite actualmente obtener una gran cantidad de imágenes de muy buena calidad con información adicional como la fecha, la hora, la temperatura y la fase lunar por mencionar algunas características (Wemmer et al. 1996; Cutler y Swan1999; Vaughan et al. 2011).

En México, las imágenes fotográficas han incrementado el conocimiento actual de los mamíferos silvestres relacionado con su diversidad (Silveira et al. 2003; Faller-Menéndez et al. 2005; Sbrek-Araujo y García 2005; Bárcenas y Medellín 2007; Lyra-Jorge et al. 2008; Cecaira-Ricoy et al. 2012; Charre-Medellín et al. 2012; Iglesias-Hernández et al. 2012), con los registros de presencia novedosos en diferentes estados del país, como el ocelote (Leoparuds pardalis) en Michoacán (Chávez-León 2005) y en Guanajuato (Sánchez et al. 2012); el agutí (Cuniculus paca) en Querétaro (Jiménez-Maldonado y López-González 2011) y el cabeza de viejo o tayra (Eira barbara) en Puebla (Ramírez Bravo 2011). También se han investigado las actividades de los tapires (Tapirus bairdii) en Quintana Roo (Pérez y Matus 2010), aspectos relacionados con el comportamiento en jaguares (Panthera onca, Faller-Menéndez et al. 2007) y otros relacionados con el comportamiento asociado al forrajeo y áreas de actividad de diferentes especies que habitan en el desierto (Elizalde-Arellano 2012).

Para estudiar las especies de mamíferos que habitan un área con base en imágenes fotográficas es muy importante reconocer a cada una de ellas con la mayor exactitud posible, lo que en ocasiones puede resultar difícil cuando las especies son similares entre sí, principalmente los mamíferos medianos o pequeños. Por lo que es de gran relevancia conocer sus principales características morfológicas para realizar una adecuada identificación.

Los objetivos de este estudio fueron documentar a través de imágenes fotográficas diferentes especies de mamíferos que habitan en la Reserva de la Biosfera de Mapimí (RBM) con la finalidad de registrar su presencia y resaltar en ellas las principales características que permiten distinguirlas con claridad, en particular aquellos casos de especies similares. Especificar también los lugares y el tipo de vegetación en donde se obtuvieron los registros y reportar también algunas de sus actividades y otros aspectos relevantes de su biología.

\section{Material y Métodos}

Área de estudio. La Reserva de la Biosfera de Mapimí (RBM) tiene una extensión de 342,388 ha y se localiza en el Desierto Chihuahuense, entre los estados de Durango, Chihuahua y Coahuila, México, entre las coordenadas $26^{\circ} 11^{\prime}-27^{\circ} 00^{\prime} \mathrm{N}$ y $-103^{\circ} 23^{\prime}-104^{\circ} 07^{\prime} \mathrm{W}$ (Figura 
1). La precipitación anual promedio es de $260 \mathrm{~mm}$ la cual se concentra en los meses de julio a septiembre (verano) y el $5 \%$ ocurre de noviembre a enero (invierno). Considerando el régimen de precipitaciones de la región pueden reconocerse dos temporadas al año: la de Iluvia (de julio a enero) y la seca (de febrero a junio). La temperatura promedio de la zona es de $28^{\circ} \mathrm{C}$ en verano y de $11.8^{\circ} \mathrm{C}$ en invierno, con fuertes variaciones estacionales y diarias de hasta $20^{\circ} \mathrm{C}$ (Cornet 1988). La topografía consiste en un área plana muy extensa en la que se forman lagunas y manantiales temporales y permanentes, interrumpida por cerros (CONANP 2006). La vegetación corresponde a un matorral xerófilo en el que se han registrado zonas de matorrales rosetófilos, crasicaules, micrófilos inermes, magueyales (Agave asperrima), nopaleras (Opuntia spp.) y grandes extensiones de pastizal de sabaneta (Hilaria mutica). Otras especies vegetales características de la Reserva son arbustos como la gobernadora (Larrea tridentata), el ocotillo (Fouquieria splendens), el mezquite (Prosopis glandulosa), la candelilla (Euphorbia antisyphilitica), la yuca (Yucca elata) y las acacias (Acacia asperrima, A. constricta y $A$. greggi; Montaña 1988; Maury 1992).

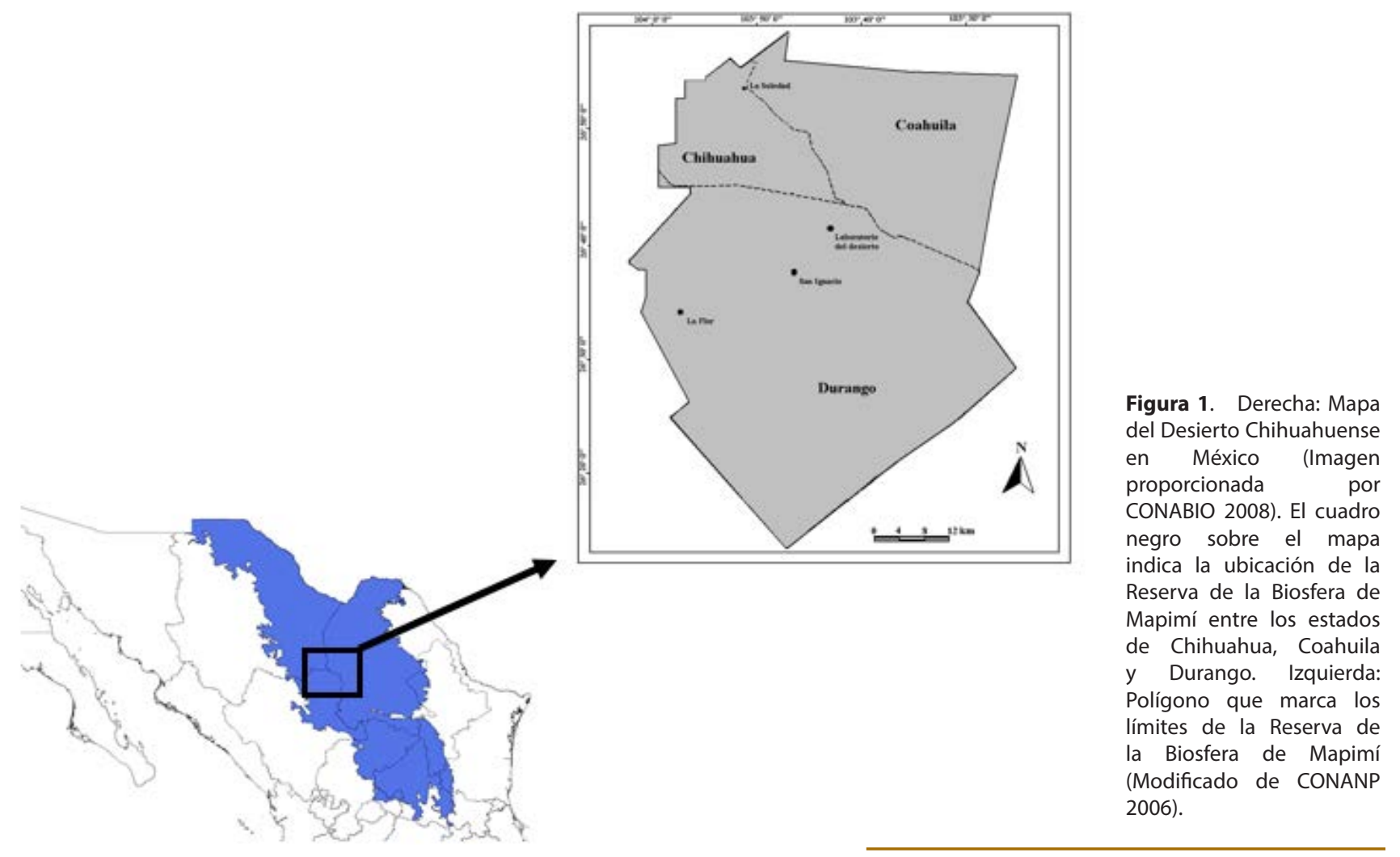

La fauna de vertebrados incluye especies en peligro de extinción como el águila real (Aquila chrysaetos) y la tortuga del desierto (Gopherus flavomarginatus), endémica de la región. La zona es hábitat también de varias especies de roedores heterómidos (como Dipodomys merriami, D. nelsoni, D. ordii, Chaetodipus nelsoni, C. penicillatus y Perognathus flavus), múridos (como Neotoma leucodon y Sigmodon hispidus), sciuridos (Xerospermophilus spilosoma, Ictidomys mexicana y Otospermophilus variegatus) así como lagomorfos (Lepus californicus y Sylvilagus audubonii). También habitan en la zona el venado bura (Odocoileus hemionus), la zorra gris (Urocyon cinereoargenteus), el tlalcoyote (Taxidea taxus), zorrillos (Spilogale putorius, Conepatus mesoleucus y Mephitis macroura), el coyote (Canis latrans), el gato montés (Lynx rufus) y el puma (Puma concolor; CONANP 2006). 
El trabajo de campo se llevó a cabo durante los meses de marzo a abril y octubre a noviembre de los años 2009 a 2014 realizando en cada ocasión estancias de 20 días en la Reserva de la Biosfera de Mapimí. Para registrar la presencia y actividad de los mamíferos principalmente herbívoros, roedores y lagomorfos, en cada estancia de campo se muestrearon simultáneamente cinco sitios diferentes de la Reserva, dos de ellos ubicados en áreas con vegetación de pastizal y tres en áreas con matorral (Hernández et al. 2011a, b).

En cada sitio se colocaron seis estaciones (tres pares) de observación constituidas por un cebo que consistió en una mezcla de $300 \mathrm{~g}$ de alfalfa comprimida y cuatro kilos de arena colocada en una charola con capacidad de seis litros, modificando a las condiciones locales el diseño propuesto por Smith y Brown (1991). Frente a cada cebo se colocó a nivel del piso y a una distancia de $1.5 \mathrm{~m}$ de distancia una cámara con sensor infrarrojo (Moultrie GameSpy, modelo D-55) las cuales permanecieron activas las 24 horas durante seis días consecutivos y programadas para tomar una secuencia de tres fotos por minuto una vez que el sensor registrara algún movimiento. En total durante cada estancia de campo se colocaron un total de 30 cámaras. En particular durante las estancias de los años 2011 a 2014 se colocaron por 15 días continuos dos cámaras trampa adicionales frente a un pequeño cuerpo de agua permanente en la falda del Cerro San Ignacio para registrar las especies de mamíferos que frecuentan esta área.

Además de lo anterior, en la RBM se han realizado diferentes proyectos relacionados con la biología de los mamíferos, i. e. se realizó la captura de algunos pumas (Laundré, com. pers.), de gatos monteses y coyotes (Elizalde-Arellano 2012; Elizalde-Arellano et al. 2012), de algunas especies de murciélagos entre las grietas de los Cerros Torrecillas, así como en las instalaciones del Laboratorio del Desierto del INECOL, y un proyecto de investigación ecológica a largo plazo (LTER- Long Term Ecological Research) sobre la fauna del desierto desde el año 1996 hasta la fecha (Hernández et al. 2011 a, b). En todos los casos los procedimientos de campo del presente estudio se ajustaron a las recomendaciones de Sikes et al. (2011). Las investigaciones mencionadas han reunido un valioso acervo de registros fotográficos obtenidos con las cámaras manuales de uso personal de los investigadores involucrados a través de los cuales se ha obtenido parte de la información que se incluye en el presente estudio.

A partir de las imágenes fotográficas se analizó el número de especies que fueron registradas por medio de cámaras trampa y/o manuales. Para cada especie se hizo una reseña en la que se destacan sus características morfológicas que pueden apreciarse de manera clara en las imágenes obtenidas y con las que es posible reconocer a cada especie. Se indica también si las imágenes se obtuvieron mediante cámaras trampa y/o manuales, así como el lugar de la RBM y el tipo de vegetación donde fueron obtenidas las fotografías. Se comentan algunas de sus actividades que han sido registradas así como otros aspectos relevantes de su biología. La nomenclatura, clasificación y orden en el que se mencionan a las especies de mamíferos en este estudio sigue la propuesta por Ceballos y Arroyo (2012).

\section{Resultados}

Por medio de las imágenes fotográficas se registraron en total a cinco órdenes, 12 familias, 27 géneros y 31 especies (Tabla 1) que representan el $49 \%$ del total conocido para la RBM. En la RBM se conocían 63 especies de mamíferos, pero en el presente estudio se registra por primera vez a los zorrillos manchados (Spilogale gracilis) lo que incrementa el número a 64. 
Con las cámaras trampa se obtuvieron 1,714 fotografías con las que se registraron cinco órdenes, 10 familias, 14 géneros y 15 especies de mamíferos (Tabla 1). El esfuerzo de muestreo de las cámaras trampa fue de seis cámaras por $144 \mathrm{~h}$ por cinco sitios por doce estancias de campo dio un total de 51,840 h. Para el cuerpo de agua en la base del Cerro San Ignacio fue de $720 \mathrm{~h}$ por ocho meses se obtuvieron $5,760 \mathrm{~h}$ de esfuerzo de muestreo. Sumando ambos esfuerzos se obtuvo un total de 57,600 h de muestreo con este método. Las especies con mayor número de registros (entre paréntesis el número de fotografías obtenidas) fueron: Dipodomys nelsoni $(n=610)$, D. merriami $(n=469)$ y Netoma leucodon $(n=335$; Figura 2$)$ y las del menor número fueron Pecari tajacu $(n=6)$, Taxidea taxus $(n=5)$, Conepatus leuconotus ( $n=$ $3)$, Otospermophilus variegatus $(n=3)$, Odocoileus virginanus $(n=2)$ y Urocyon cinereoargenteus $(n=1)$. Las especies con menor número de registros no están incluidas en la Figura 2. Las especies registradas en el cuerpo de agua fueron Lynx rufus $(n=17)$, Conepatus leuconotus $(n=$ $3)$, Otospermophilus variegatus $(n=3)$ y Pecari tajacu $(n=6)$.

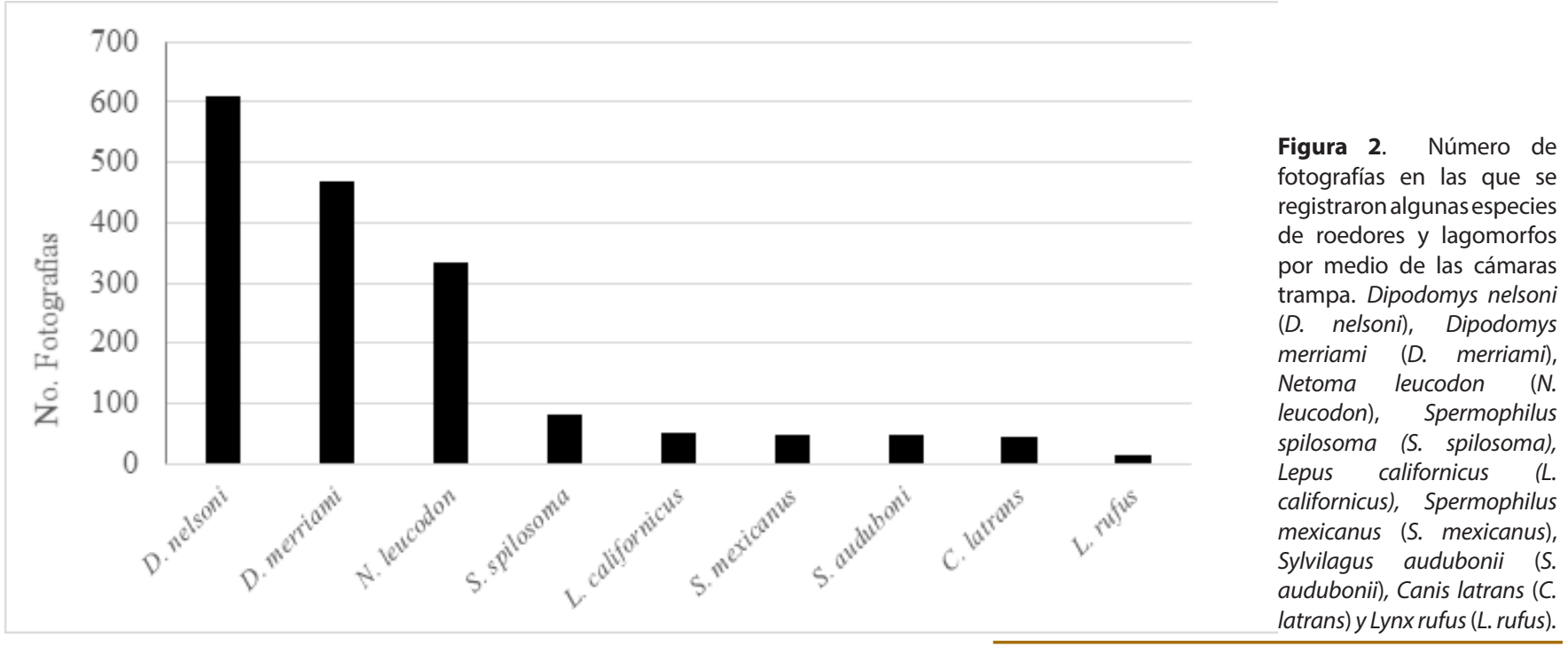

Con las cámaras manuales se obtuvieron más de 2,000 fotografías con las que se registraron 30 especies, de las cuales 16 se registraron únicamente por este medio y son: Vulpes macrotis, Puma concolor, Mephitis macroura, Mephitis mephitis, Spilogale gracilis, Choeronycteris mexicana, Antrozous pallidus, Chaetodipus nelsoni, Chetodipus penicillatus, Dipodomys ordii, Perognathus flavus, Reithrodontomys megalotis, Peromyscus eremicus, Peromyscus maniculatus, Onychomys torridus y Sigmodon hispidus (Tabla 1).

Se obtuvieron 382 fotografías con las cámara trampa además de otras imágenes registradas con las cámaras personales de mamíferos que solo pudieron ser identificados a nivel de género (Myotis sp., Chaetodipus sp., Peromyscus sp., Ictidomys o Xerospemorphilus) debido a que sus características no se apreciaban claramente para poder reconocer la especie a la que pertenecen. Los pecaríes de collar (Pecari tajacu) fueron los únicos que se registraron solo mediante cámaras trampa.

A continuación se mencionan las principales características morfológicas que distinguen a cada una de las especies para identificarlas a través de fotografías, las zonas de las RBM donde fueron registradas, los periodos de actividad así como algunas de sus actividades observadas y otros aspectos que se documentaron para algunas de ellas. 


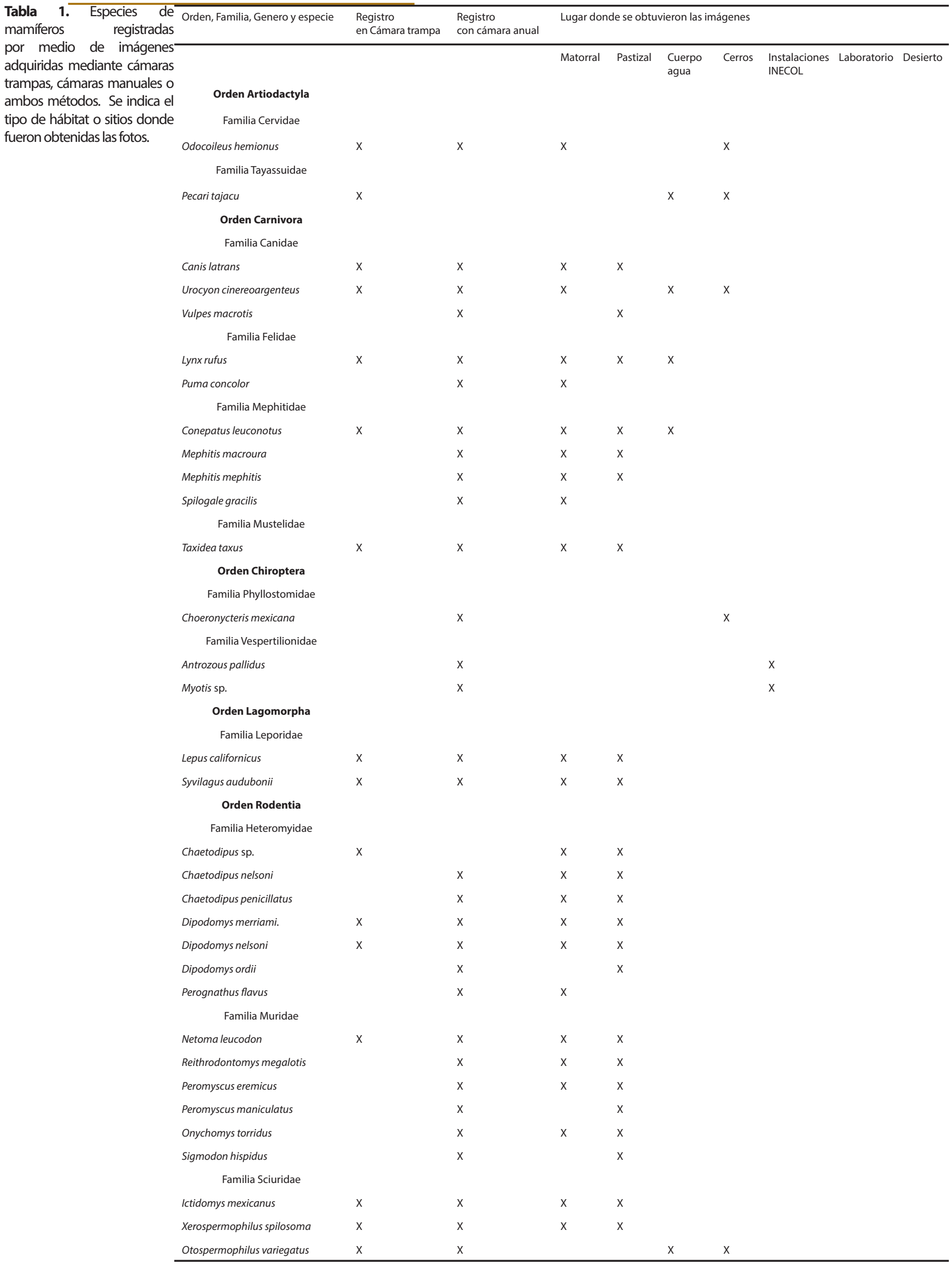




\section{Orden Artiodactyla}

\section{Familia Cervidae}

Odocoileus hemionus. Los venados bura son muy comunes en las zonas cercanas a los cerros, su aspecto es inconfundible por lo que se reconocen sin problema en las imágenes. Los machos presentan astas dicotómicamente bifurcadas durante la época de reproducción, las cuales se observaron con su desarrollo máximo en el mes de marzo (Figura 3a). Estos animales se registraron con poca frecuencia a través de las cámaras trampa ya que los cebos estaban colocados a nivel del piso con la finalidad de atraer lagomorfos y roedores. Es más frecuente registrarlos por medio de las cámaras de uso manual en los periodos diurnos (Figura 3a, Tabla 1) en particular en las laderas de los Cerros San Ignacio y Torrecillas.

\section{Familia Tayassuidae}

Pecari tajacu. Los pecaríes de collar habitan en las laderas de los cerros y pueden identificarse fácilmente por su aspecto, su color general negro y banda blanca en el cuello. Esta especie solo se registró mediante cámaras trampa (Figura 3b). Se observaron solos o en grupos familiares (piaras) y están activos durante distintas horas del día. Se registraron en el pequeño cuerpo de agua monitoreado en la ladera del Cerro San Ignacio (Tabla 1).

\section{Orden Carnivora}

\section{Familia Canidae}

Canis latrans. Los coyotes son muy abundantes en la RBM. Sus orejas puntiagudas, pelaje amarillento y su cola esponjada les confieren su aspecto característico por lo que se distinguen con facilidad en las imágenes. Se observaron mediante las trampas cámara en todas las zonas del estudio y siempre se registró solo un ejemplar por foto y están activos a diferentes horas del día y la noche. También se registraron con frecuencia mediante las cámaras de uso manual, ya que se capturan continuamente (Tabla 1).

Urocyon cinereoargenteus. Las zorras grises se distinguen por su coloración dorsal grisácea y la nuca y vientre rojizo, la cola esponjada es grisácea con una línea longitudinal negra. Estas son muy abundantes en la RBM y se registraron con mayor frecuencia en las laderas de los cerros, y menos frecuentemente en las zonas planas de pastizales y dunas. Su registro en las cámaras trampa fue muy escaso y con ellas solo se observaron en la ladera del Cerro San Ignacio, se registraron con mayor frecuencia a través de las cámaras manuales durante los periodos nocturnos (Tabla 1).

Vulpes macrotis. Estas zorritas se distinguen de las zorras grises porque su dorso es café claro, sus orejas son grandes y puntiagudas, la cola es esponjosa y de forma cilíndrica con la punta de color negro y por lo general la mantienen en posición recta (Figura 3c). Son muy poco frecuentes en la RBM y se encontraron al norte de ésta en la zona de dunas y solo se registraron a través de cámaras manuales (Tabla 1). Se desconoce su periodo de actividad en la RBM, pero probablemente son de actividad nocturna. 


\section{Familia Felidae}

Lynx rufus. Los gatos monteses son abundantes en la RBM. Se caracterizan por su pelaje moteado, los mechones de pelos en la punta de sus orejas y la cola corta. Se han registrado tanto en las zonas de matorral como en las de pastizal y en los cerros. Su registro a través de las cámaras trampa fue escaso y se registraron con mayor frecuencia mediante las cámaras manuales durante los periodos de trampeo (Tabla 1). Están activos durante las horas crepusculares.

Puma concolor. Los pumas son poco frecuentes en la RBM y se encuentran en las zonas de los cerros y cercanas a los cuerpos de agua (Figura 3d). Se caracterizan por su pelaje corto y de color amarillo, su aspecto es inconfundible y pueden identificarse claramente en las imágenes. Su presencia en la RBM se reconoce también a través de huellas, excretas y avistamientos ocasionales. Se registraron únicamente con cámaras manuales ya que se capturaron ocasionalmente en la zona (Tabla 1). Estudios preliminares indican que algunos ejemplares rastreados mediante telemetría no residen en la RBM, posiblemente debido a una baja densidad de venados que son sus presas principales, por lo que estos avistamientos corresponden a ejemplares que transitan temporalmente por la zona (Laundré com. pers.).

Familia Mephitidae

Conepatus leuconotus. Estos zorrillos son poco frecuentes en la RBM. Es posible distinguirlos por su banda dorsal ancha de color blanco, su cola corta completamente blanca y el cojinete de su nariz grueso y desnudo (Figura 3e). Se observaron en la ladera del Cerro San Ignacio mediante cámaras trampa y con una mayor frecuencia con imágenes obtenidas manualmente ya que fueron capturados ocasionalmente (Tabla 1) durante los periodos nocturnos, por lo que las zonas rocosas y las faldas de los cerros favorecen su presencia en el desierto.

Mephitis macroura. Los zorrillos de esta especie también se observaron con poca frecuencia en la RBM. Se distinguen porque presentan dos bandas blancas laterales que recorren el cuerpo desde la nuca hasta la cadera, la cola tiene largos pelos de color negro y una menor cantidad de pelos blancos. Se registraron únicamente por medio de cámaras manuales (Tabla 1) ya que algunos de ellos fueron capturados en la ladera del Cerro San Ignacio así como también en la zona de dunas durante los periodos nocturnos.

Mephitis mephitis. Esta especie de zorrillo también se observaron con poca frecuencia en la RBM. Se distinguen de M. macroura porque la banda dorsal blanca se divide en dos laterales en la parte media del dorso y continúa hasta la cadera. Al igual que M. macroura también fueron registrados únicamente con cámaras manuales y se capturaron en la ladera del Cerro San Ignacio así como en la zona de dunas (Tabla 1) también durante los periodos nocturnos.

Spilogale gracilis. Estos zorrillos representan un nuevo registro en la RBM. Se distinguen por sus numerosas bandas longitudinales de color blanco alternadas con negro en su parte dorsal. Se atraparon ocasionalmente en la ladera del Cerro San Ignacio (Figura 3f), en zonas rocosas con vegetación de nopalera las cuales son favorables para estos organismos. Solo fueron registrados por medio de cámaras manuales (Tabla 1) y están activos también durante las horas nocturnas.

Familia Mustelidae

Taxidea taxus. Los tlalcoyotes o tejones son muy poco frecuentes en la RBM. Se caracterizan por tener un cuerpo robusto y patas cortas, su pelaje es una combinación de negro con blanco y presentan características marcas blancas y negras en el rostro. Están presentes en zonas de 
matorral, de pastizal y en las dunas, no gustan de áreas rocosas, en general, sin embargo se les ha registrado por medio de cámaras trampa (Figura $3 \mathrm{~g}$ ) y cámaras manuales (Tabla 1). Estos animales se observaron durante horas diurnas y nocturnas.

\section{Orden Chiroptera}

Familia Phyllostomidae

Choeronycteris mexicana. Estos murciélagos se caracterizan por tener un hocico largo (Figura 3 h) relacionado con su alimentación nectarívora, tienen un uropatagio y cola cortos y su coloración dorsal es parda y la ventral gris, lo que los distingue claramente en las imágenes. Habitan en grietas en las zonas rocosas y los cerros de la RBM. A lo largo del estudio solo se encontraron cinco ejemplares en el Cerro Torrecillas en donde se registraron únicamente mediante cámaras manuales (Tabla 1).

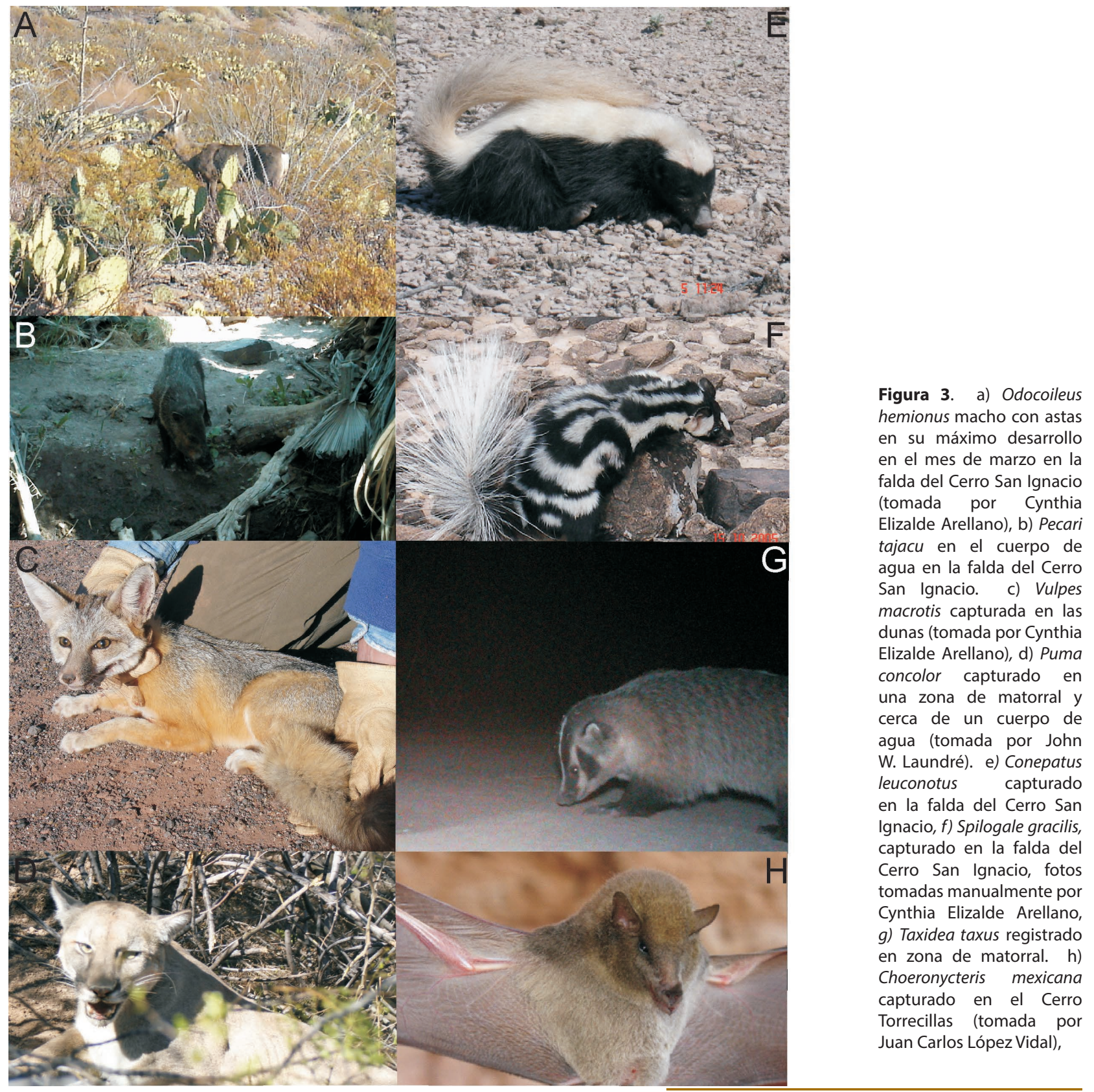


Familia Vespertilionidae

Antrozous pallidus. Estos murciélagos insectívoros se encuentran con frecuencia agrupados en diferentes partes de la RBM. Se reconocen en las imágenes por su pelaje café claro en el dorso y blanco en el vientre y por sus grandes orejas. Se les ha observado en grupos de entre 10 y 20 individuos en grietas entre las rocas en el afloramiento rocoso conocido como Espinazo del Diablo. También se han encontrado perchados en las instalaciones del Laboratorio del Desierto (Tabla 1), sede de la Reserva, lo que permitió la obtención de las fotografías por medio de cámaras manuales (Figura 4a). Esta especie forma grupos que varían desde seis hasta 30 individuos en los que la mayoría de ellos son hembras reproductivamente inactivas. Se encuentran en este lugar después de las $21 \mathrm{~h}$ y lo emplean como refugio nocturno en el cual dormitan y digieren su alimento, dejando una gran cantidad de excretas debajo de los sitios donde se perchan y al amanecer abandonan el lugar.

Myotis sp. En la RBM se han registrado varias especies de este género de murciélagos como son $M$. californicus, M. velifer y M. ciliolabrum. Se han observado ejemplares de diferentes especies perchados ocasionalmente en las instalaciones del Laboratorio del Desierto, lo que permitió también su registro fotográfico a través de las cámaras manuales (Tabla 1), entre ellas se encontró a M. californicus (Figura 4b) que son solitarios y una especie no identificada (M. sp.) que se percha en pequeños grupos de cuatro a seis individuos.

\section{Orden Lagomorpha}

\section{Familia Leporidae}

Lepus californicus. Las liebres son muy abundantes en la RBM, su aspecto en las imágenes es inconfundible debido a sus largas orejas con una marca negra en la parte dorsal de las mismas. Se observaron en las áreas de matorral y pastizal pero rara vez comieron el alimento ofrecido, más bien mostraron un comportamiento de recelo (Figura 4c), por lo que fueron registradas con muy poca frecuencia en las cámara trampa y con mayor frecuencia mediante cámaras manuales (Tabla 1).

Syvilagus audubonii. Los conejos en las imágenes se observan más pequeños que las liebres, de cuerpo robusto y redondeado, muestran una mancha rojiza en la nuca, sus orejas, patas y cola son más cortas también (Figura 4d) y el color blanco de la porción ventral de su cola es distintivo. Se observaron con mayor frecuencia en áreas de matorral que en pastizal (Figura 4d) y frecuentemente se registraron a través de las cámaras trampa consumiendo el alimento proporcionado y en ocasiones también se registraron con las cámaras manuales (Tabla 1).

\section{Orden Rodentia}

\section{Familia Heteromyidae}

Chaetodipus sp. Estos roedores se caracterizan por su coloración café oscuro, orejas pequeñas y redondeadas, su cola es larga y termina en un mechón largo de pelos a manera de pincel. En la RBM se han registrado dos especies de este género, C. nelsoni y C. penicillatus, ambas en las áreas de matorral y pastizal (Tabla 1). En las imágenes obtenidas con cámaras trampa no es posible distinguir la especie a la que pertenecen, ya que las características 
para diferenciarlas están relacionadas a los pelos de la cadera y deben verse directamente en los ejemplares, por lo que los registros obtenidos de esta manera pueden reconocerse únicamente a nivel de género. Cuando es posible capturarlos y registrarlos mediante cámaras manuales si pueden distinguirse por sus características morfológicas, como se comenta posteriormente. Estos ratones hicieron varias visitas a las charolas con cebo y trasladaron el alimento en sus abazones. Cuando en la misma imagen se registró a Chaetodipus y Dipodomys simultáneamente, los primeros se mantuvieron fuera de la charola mientras los últimos se alimentaban de la comida ofrecida. Las observaciones directas de esta interacción mostraron que los individuos del género Chaetodipus entran a las charolas a alimentarse después de que los individuos del género Dipodomys abandonaron el sitio.

Chaetodipus nelsoni. Se han registrado predominantemente en zonas de matorral. Son de las especies de roedores más abundantes en la zona. Se distinguen de C. penicillatus por tener una coloración sal y pimienta (Figura 4e) y la presencia de pelos gruesos en la cadera semejando espinas, características que se observaron por su captura directa y las imágenes se obtuvieron con las cámaras manuales (Tabla 1).

Chaetodipus penicillatus. Esta especie está presente tanto en el matorral en donde comparte el área con C. nelsoni, como en el pastizal en donde es más abundante y codominante. Se distingue de la anterior especie en que es de color ante y su coloración en general es uniforme. Los pelos de la cadera son muy delgados y rizados hacia arriba (Figura 4f). Son de las especies de roedores más abundantes en la RBM, se obtuvieron mediante captura directa y las imágenes se obtuvieron con las cámaras manuales (Tabla 1).

Dipodomys merriami. Los ratones de esta especie se observaron en imágenes obtenidas con las cámaras manuales y con las cámaras trampa, con las cuales es posible distinguirlas claramente porque tienen las patas traseras largas para la locomoción a saltos y la punta de la cola obscura (Figura 4g). Se les ha registrado en la zona de dunas, en áreas con vegetación de pastizal y en zonas de matorral xerófilo cercano a los cerros (Tabla 1). Estos roedores hacen varias visitas durante la misma noche a las charolas con alimento hasta consumirlo completamente.

Dipodomys nelsoni. Estos roedores se caracterizan por tener la punta de la cola blanca (Figura 4h), lo que permite reconocerlos a través de las imágenes. Se registraron mediante las cámaras trampa y manuales principalmente en la zona de dunas (Tabla 1) a diferentes horas de la noche y madrugada. Los ejemplares visitan varias veces las charolas y se llevan el alimento en sus abazones a sus madrigueras, dejando vacías las charolas.

Dipodomys ordii. Estos roedores son de tamaño y apariencia similar a D. merriami pero se distinguen de estos porque presentan un quinto dedo muy pequeño en sus patas traseras. Habitan pastizales muy abiertos y cortos y en las dunas tanto móviles como estabilizadas, son particularmente abundantes en las dunas móviles. Solo se registraron mediante las cámaras manuales (Tabla 1) durante los periodos de captura nocturna.

Perognathus flavus. Estos ratones se caracterizan por presentar una mancha amarillenta detrás de cada oreja (Figura 5a). Se observan con alguna frecuencia durante las horas tempranas de la noche saltando entre los arbustos a la orilla de los caminos de terracería, estos pequeños roedores son poco abundantes y frecuentan tanto los matorrales y pastizales como las dunas. Solo se registraron mediante las cámaras manuales (Tabla 1). 


\section{Familia Muridae}

Netoma leucodon. Las ratas nopaleras se reconocen en las fotos porque son de color gris en el dorso y blanco en el vientre, sus orejas son de tamaño mediano y su cola es gruesa y bicolor. Son muy abundantes en la RBM, se han registrado por medio de cámaras trampa y manuales tanto en zonas de pastizal como de matorral (Tabla 1). Al igual que las ratas canguro visitaron las charolas con cebo de alfalfa varias veces durante la noche y aunque éstas no cuentan con abazones para trasladar alimento también lo acarrean y lo acumulan en sus madrigueras.

Reithrodontomys megalotis. Estos ratones se distinguen de otros múridos de la zona por su color café oscuro, sus orejas son cortas y cubiertas de pelo y su cola es larga y delgada (Figura 5b). Esta es una especie principalmente de pastizal, aunque también frecuenta los matorrales, solo se registró por medio de cámaras manuales durante las capturas nocturnas (Tabla 1). En general es una especie poco abundante en la RBM que por lo regular incrementa su abundancia posteriormente a los años con elevados niveles de lluvia.

Figura 4. a) Antrozous pallidus perchados en las instalaciones del Laboratorio del Desierto (tomada por Cynthia Elizalde Arellano), b) Myotis californicus perchados en las instalaciones del Laboratorio del Desierto (tomada por Cynthia Elizalde Arellano). c) Lepus californicus en la zona de dunas, d) Sylvilagus audubonii en una de las zonas de matorral. e) Chaetodipus nelsoni capturado en una zona de matorral (tomada por Alberto González Romero), f) Chaetodipus penicillatus, se distinguen los pelos delgados de la cadera que los caracteriza, ejemplar capturado en una zona de pastizal (tomada por Alberto González Romero), g) Dipodomys merriami. Se distingue por la punta de su cola café, h) Dipodomys nelsoni. Se distingue por la punta de su cola blanca.

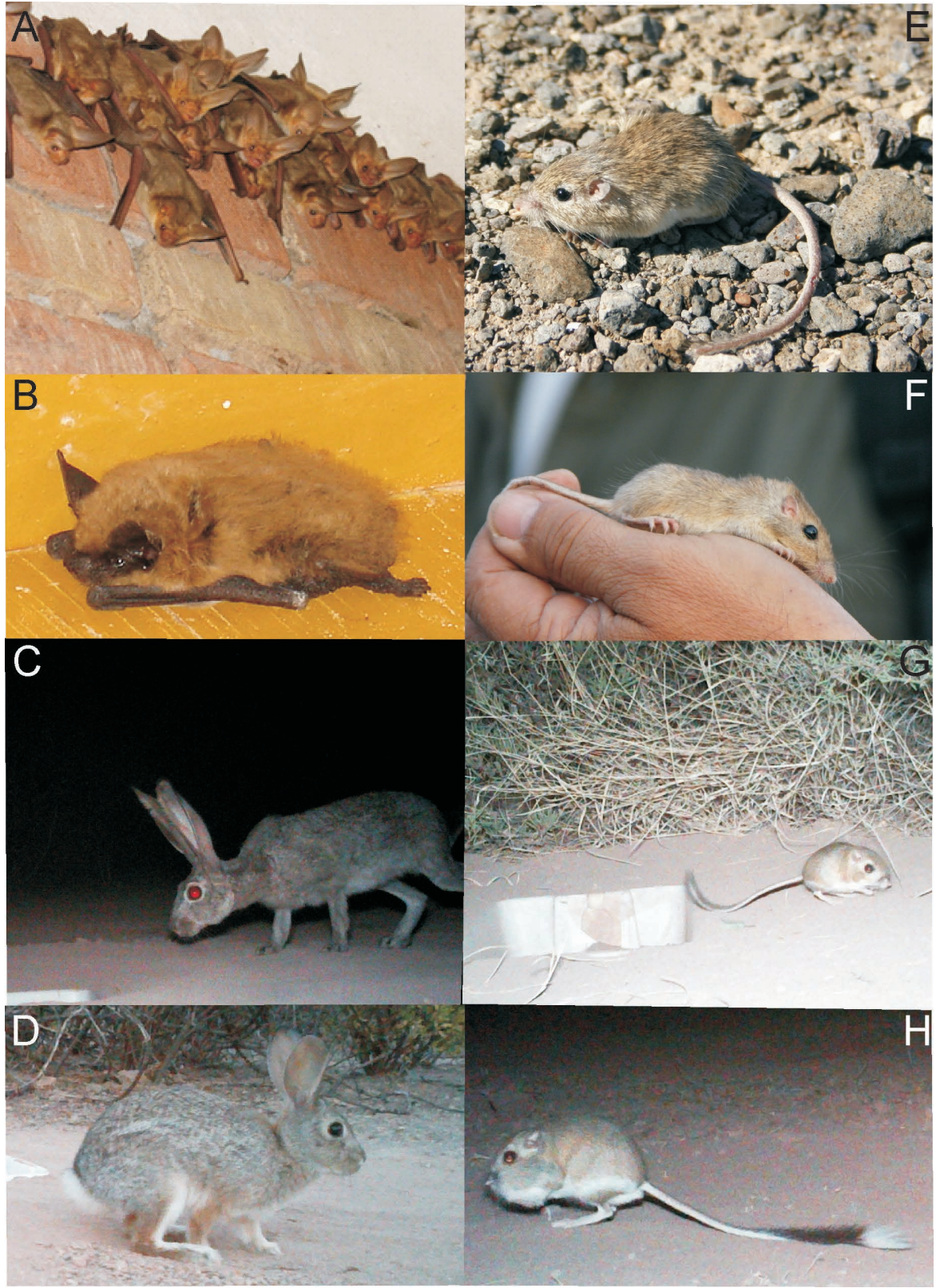


Peromyscus eremicus. Estos ratones se caracterizan por la coloración de su pelaje de gris, pardo y negro, aunque en ocasiones presentan tintes café amarillentos, su cola es larga y con poco pelo (Figura 5c). Son muy abundantes en la RBM, tanto en el matorral como en los pastizales con mezquites, es frecuente encontrarlos también en las dunas estabilizadas sobre todo donde hay vegetación densa. Se registraron solo mediante cámaras manuales (Tabla 1) durante los periodos nocturnos.

Peromyscus maniculatus. Es una especie similar a $P$. eremicus, pero su coloración es gris clara en el dorso y blanco en el vientre, manos y patas. Se distingue fácilmente de la especie anterior por su aspecto general, su cola corta delgada y marcadamente bicolor, negra dorsalmente y blanca ventralmente. En general son muy escasos y generalmente se encuentran en el pastizal en donde incrementa su tamaño poblacional durante los años en los que hubo una temporada de lluvias abundante. Estos ratones son de actividad nocturna y llegan a ser una plaga agrícola fuera de la RBM. Se registraron solo mediante cámaras manuales (Tabla 1).

Onychomys torridus. Son roedores que se caracterizan por tener un pelaje pardo mezclado con blanco en el dorso y tienen la cola corta y muy gruesa con la parte ventral y distal blanca (Figura 5d). Se han registrado de manera muy escasa en la RBM tanto en la zona de pastizal como de matorral. Son de actividad nocturna y su alimentación es carnívora por lo que pueden consumir insectos y pequeños vertebrados como lagartijas y ratones, los insectos tenebrionidos conocidos como pinacates son una parte importante dentro de su dieta, por lo que tienen un característico olor como a vinagre. Se desconoce una gran parte de la información de su biología en la RBM. Se registraron solo mediante cámaras manuales (Tabla 1).

Sigmodon hispidus. Estos roedores se distinguen por su cuerpo robusto, cuello corto orejas pequeñas cubiertas de pelo y su coloración sal y pimienta es característica de ellos, con el pelo largo y áspero (Figura 5e). Su presencia en la RBM es escasa y se han registrado principalmente en pastizales después de varios años de lluvias regulares. Son de actividad nocturna y fuera de la RBM llega a convertirse en una plaga agrícola. Se registraron solo mediante cámaras manuales (Tabla 1).

Familia Sciuridae

Ictidomys mexicanus. Son ardillas terrestres que se caracterizan por presentar líneas formadas por puntos blancos que recorren longitudinalmente el dorso, lo que permite reconocerlas claramente en las fotografías en particular las de trampas cámara (Figura 5f). Son de actividad diurna y están muy activas durante las horas con las mayores temperaturas en la zona, inclusive cuando ésta alcanza los $40^{\circ} \mathrm{C}$. Se observó que éstas acumulan el alimento en sus abazones y los transportan a sus madrigueras, que se encontraron aproximadamente a 10 metros de las charolas. Se observaron en áreas de matorral y pastizal, mediante cámaras trampa y manuales (Tabla 1).

Otospermophilus variegatus. Estas ardillas tienen un pelaje que presenta una mezcla de color blanco y negro que al combinarse da un aspecto gris jaspeado (Figura $5 \mathrm{~g}$ ). Están asociadas a las zonas rocosas en las laderas de los cerros y se han encontrado con muy poca frecuencia y se han registrado mediante cámaras trampa y manuales (Tabla 1). Se desconoce su abundancia y sus relaciones ecológicas en la RBM.

Xerospermophilus spilosoma. Se caracterizan por tener color dorsal amarillento claro y presentar puntos blancos arreglados de forma irregular sobre el dorso, lo que permite 
reconocerlas en imágenes obtenidas con las cámara trampa (Figura 5h). También son de actividad diurna y se les ha registrado en las horas con la mayor temperatura de la zona, inclusive a $40{ }^{\circ} \mathrm{C}$. Acumulan alimento en sus abazones internos y lo transportan a sus madrigueras. Se observan en áreas de matorral y pastizal, mediante cámaras trampa y manuales (Tabla 1).

Debido a la gran semejanza entre $I$. mexicanus y $X$. spilosoma en ocasiones es difícil distinguirlas por medio de fotografías obtenidas con las cámaras trampa si éstas no son lo suficientemente claras para ello, debido a que en ocasiones la perspectiva o el perfil de la foto dificultan su identificación, por lo que no todas las imágenes de estas pueden identificarse a nivel específico.

Figura 5. a) Perognathus flavus capturado en una zona de matorral (tomada por Alberto González Romero). b) Reithrodontomys megalotis capturado en una zona de matorral, c) Peromyscus eremicus capturado en una zona de matorral, d) Onychomys torridus capturado en una zona de matorral, e) Sigmodon hispidus capturado en una zona de pastizal (todas las fotos fueron tomadas por Alberto González Romero). f) Ictidomys mexicanus. Se distinguen claramente las líneas y los puntos blancos en el dorso, ejemplar registrado en una zona de matorral, g) Otospermophilus variegatus observada en la falda del Cerro Torrecillas (tomada por Juan Carlos López Vidal), h) Xerospermophilus spilosoma. Los puntos blancos son muy tenues y no se presentan alineados en su dorso, ejemplar registrado en una zona de matorral.

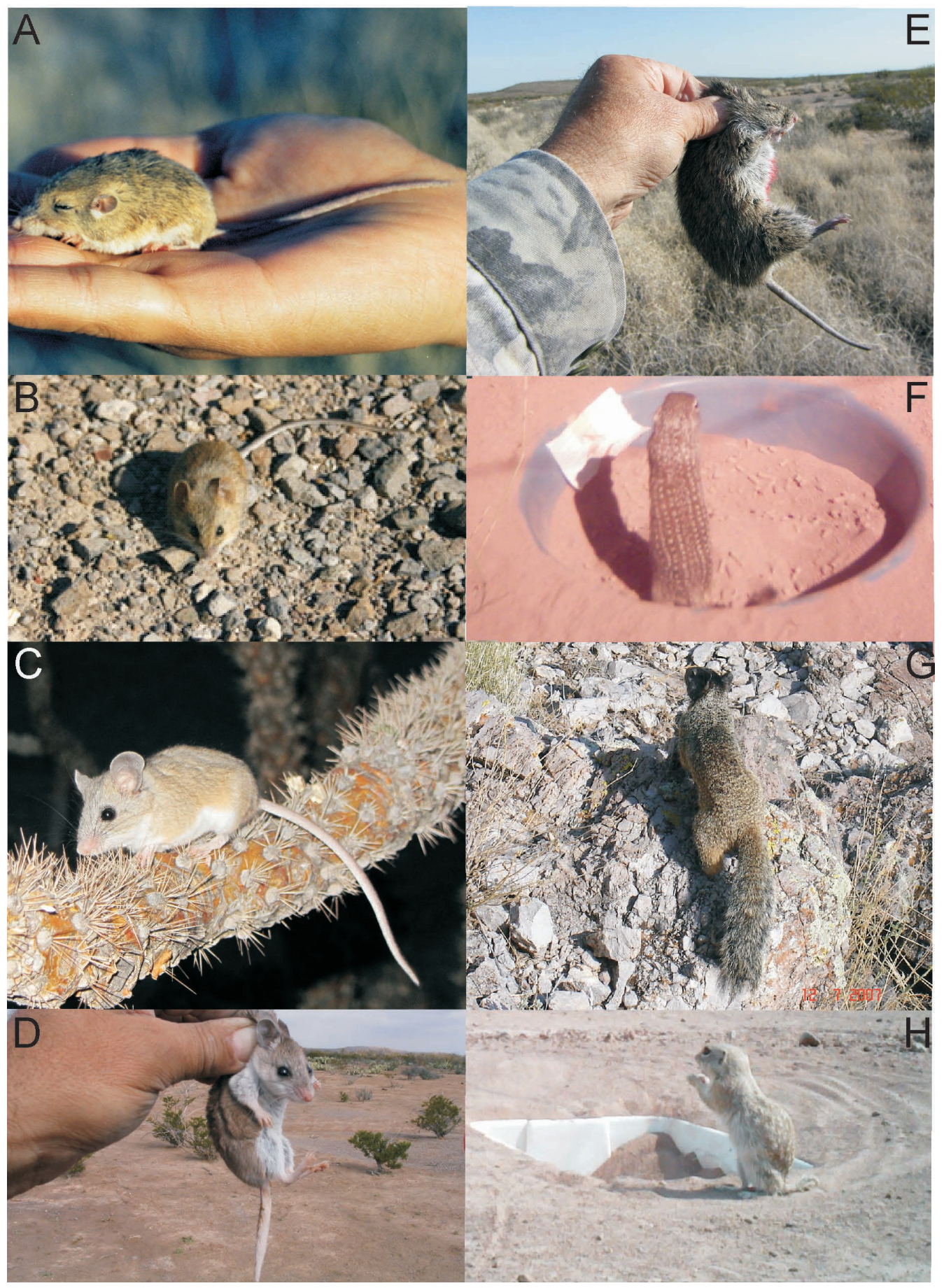


Aun cuando en la Reserva de la Biosfera de Mapimí se han registrado hasta 64 especies de mamíferos (Aragón y Garza 1999) es importante notar que existen especies con muy poca probabilidad de ser registradas mediante cámaras trampa, debido a su tamaño pequeño (como los murciélagos y varias especies de roedores), a que son especies poco abundantes o muy elusivas (como diferentes especies de zorrillos y los pumas) o a que únicamente se han registrado mediante rastros (como los mapaches por medio de huellas, Aragón y Garza, 1999). Asimismo cabe la posibilidad de que las cámaras se hayan colocado en sitios poco frecuentados por estas especies.

De acuerdo con los resultados obtenidos, el uso de las cámaras trampas es una herramienta valiosa y útil que permite conocer diferentes aspectos de numerosas especies de mamíferos en esta y otras áreas de México y el mundo, incrementando los detalles sobre su biología como horas de actividad, preferencia de hábitat, algunas interacciones entre ellas, así como inventarios de especies de talla mediana y grande como carnívoros y ungulados (Silveira et al. 2003, Sbrek-Araujo y Garcia 2005, Lyra-Jorge et al. 2008) e incluso roedores (este estudio). Sin embargo esta metodología no puede sustituir en su totalidad a la captura directa de algunas especies en la RBM, en particular aquellas de tamaño pequeño como roedores, murciélagos e incluso carnívoros, debido a que este método es necesario para la correcta identificación de diferentes especies e inclusive para registrar su sola presencia en la localidad, como es el caso de los roedores Reithrodontomys megalotis, Peromyscus eremicus, P. maniculatus e incluso los zorrillos Spilogale gracilis entre otras.

Considerando lo anterior, es recomendable que para los estudios cuyo objetivo principal sea el inventario de especies las cámaras trampa sean empleadas para especies de tamaño mediano a grande y complementar el trampeo directo enfocado principalmente a especies de tamaño mediano y pequeño (Silveira et al. 2003; Sbrek-Araujo y Garcia 2005; Lyra-Jorge et al. 2008).

La identificación de los venados en general es clara por medio de las cámaras trampas y manuales debido a sus características distintivas. Estos mamíferos prefieren las zonas de cerros y las zonas planas cercanas a éstos en la RBM (Sánchez-Rojas y Gallina 2000a; EsparzaCarlos et al. 2011) en donde se ha registrado su mayor densidad, que varía entre 0.7 a 4.21 venados $/ \mathrm{km}^{2}$ entre los diferentes cerros de la RBM, con relación a las temporadas anuales y a las condiciones ambientales de cada año (Sánchez-Rojas y Gallina 2000b). En estas áreas de la RBM encuentran su principal fuente de alimentación que se compone de una variedad de hierbas durante la temporada húmeda del año, en tanto que en la temporada seca consumen candelilla y cactáceas. La forma en la que los venados usan el hábitat en la RBM depende de la distribución y disponibilidad del alimento, de la abundante cobertura vegetal que influye sobre su percepción del paisaje relacionada con el riesgo de depredación por pumas determina el uso del hábitat de los venados en esta localidad (Esparza-Carlos et al. 2011), así como también de la topografía irregular del terreno y la distancia a los cuerpos de agua (Sánchez-Rojas y Gallina 2000a).

De acuerdo a nuestros resultados, los pecaríes se observan difícilmente de manera directa en la RBM, por lo que los registros que se tienen de ellos se hicieron a través de las cámaras trampa únicamente. Estos organismos se reúnen en grupos familiares de cinco a 10 individuos que habitan en las laderas y partes bajas de los Cerros San Ignacio (en donde 
se obtuvo el registro de esta investigación) y Torrecillas en donde se pueden observar de manera ocasional. Al igual que los venados, es en estas áreas de la RBM en donde encuentran la mayor parte de su alimento que consiste en nopales (Opuntia rastrera), frutos de mezquites (Prosopis glandulosa) y tallos diversos (con frecuencias de consumo $77.58 \%$, $10.35 \%$ y $5.09 \%$ respectivamente, Ramírez Silva 2000). Es importante mencionar que los pecaríes fueron introducidos en la RBM durante la década de 1990 (Grajales-Tam com. pers. y Hernández com. pers.) puesto que de manera natural no se distribuyen en el Altiplano mexicano (Villa y Cervantes 2003). Su distribución en la RBM era marginal y se restringían a las laderas de las grandes sierras, actualmente pueden encontrarse en el centro de la RBM y se registran como parte de la fauna de la región (CONANP 2006).

Los coyotes y los gatos monteses son dos de las especies más abundantes en la RBM (Delibes et al. 1986; Hernández et al. 1993) que se pueden distinguir claramente en las imágenes obtenidas mediante trampas cámara y manuales por sus características morfológicas, y ambos carnívoros se encuentran en las diferentes áreas de la misma. Durante las décadas de los años 1980 y 1990 diferentes estudios mencionaban que los coyotes habitaban de preferencia las áreas planas de la RBM mientras que los gatos monteses lo hacían principalmente en los cerros y áreas rocosas (Delibes et al. 1986; Delibes e Hiraldo 1987; Hernández et al. 1993; Hernández y Delibes 1994; Hernández et al. 1994). Estudios recientes muestran que los gatos y los coyotes pueden encontrarse tanto en las zonas planas como en los cerros (Arias del Razo et al. 2012; López-Vidal 2014; López-Vidal et al. 2014), los gatos monteses en particular muestran una fuerte preferencia por zonas con vegetación densa tanto en las áreas planas como en los cerros (López-Vidal 2014), mientras que los coyotes no muestran una clara preferencia por áreas con o sin cobertura vegetal (Arias del Razo et al. 2012). Ambos depredadores son de actividad crepuscular (Hernández et al. 1993; Arias del Razo et al. 2012; Elizalde-Arellano et al. 2012).

Las zorras grises también son cánidos muy abundantes que pueden encontrarse en diferentes zonas de la RBM. Gran parte de su biología en la localidad se desconoce, excepto por la composición de su dieta que se basa principalmente en roedores (ardillas - Otospermophilus variegatus, ratas canguro - Dipodomys spp y otros - Chaetodipus spp.) y diversos frutos (de cactáceas - Opuntia sp., vainas de mezquite - Prosopis glandulosa, frutos de biznaga - Ferocactus hamathacantus y de chaparro amargoso - Castela texana, Hernández et al. 1989). En lo que respecta a las zorritas del desierto (Vulpes macrotis) se han registrado muy rara vez en la localidad y al igual que para las zorras grises no existen detalles de su biología en la RBM, excepto por la composición de su dieta que incluye roedores principalmente (Dipodomys spp. con una frecuencia de consumo del $45 \%$, otros mamíferos pequeños $45 \%$ y lagomorfos $29 \%$, Hernández y Delibes 1985).

Los pumas son escasos en la RBM, únicamente se registraron mediante cámaras manuales durante un periodo de cuatro años en los que se logró capturar tres ejemplares con la finalidad de seguir sus movimientos por medio de collares radiotransmisores (Laundré com. pers.); sin embargo, estos ejemplares no pudieron rastrearse por un periodo prolongado por lo que no se obtuvo suficiente información para su estudio. Este aspecto indica que no existe una población de estos depredadores establecida en la RBM y los ejemplares capturados solo iban de paso (J. W. Laundré com. pers.). Sin embargo personal de la CONANP (com. pers.) ha registrado con cierta frecuencia avistamientos de hembras con crías en las áreas montañosas de la Reserva. 
Lo anterior indica que los pumas ocupan los terrenos menos accesibles de la RBM, lo que los hace particularmente elusivos y difíciles de estudiar, como ocurre de manera general en otras localidades (Sunquist y Sunquist 2002). La información anterior es la primera que se tiene sobre los aspectos ecológicos de los pumas en la RBM, por lo que es conveniente incrementar los esfuerzos para obtener más información sobre estos organismos.

El patrón de coloración de las diferentes especies de zorrillos son las características principales que permiten reconocer a estas especies en las imágenes, aunque en el caso particular de la RBM todas las especies fueron registradas únicamente mediante cámaras manuales. La presencia de los zorrillos manchados (Spilogale gracilis) es notable, ya que a pesar de que los mamíferos han sido uno de los grupos más estudiados en la RBM no existían registros publicados en la localidad, a pesar de haberse capturado y registrado en fotografías anteriormente. La captura directa de varios ejemplares de esta especie representan el primer registro para la RBM, lo que incrementa la diversidad de estos animales a cuatro especies de zorrillos, además de las ya conocidas: Conepatus leuconotus, Mephitis macroura, y M. mephitis (Aragón y Garza 1999; CONANP 2006), cuyas capturas indican que estos animales tienen preferencia por las zonas rocosas y cerros de la RBM donde se observaron con mayor frecuencia. La información que existe acerca de las especies de zorrillos así como de los tlalcoyotes (Taxidea taxus) en la RBM es escasa, por lo que la información del presente estudio es la primera que se tiene para estos organismos además de la de su presencia en la localidad y merece la pena dedicar esfuerzos para su investigación (Aragón y Garza 1999; CONANP 2006).

Los murciélagos en general tienen poca representación en imágenes fotográficas, tanto manuales como automáticas, esto probablemente se debe a que su captura y observación en la Reserva es poco frecuente y no muy fácil de lograr porque éstos organismos son muy móviles debido a su locomoción mediante el vuelo y aunado a ello, la RBM es una zona de gran extensión y en su mayor parte plana, en donde la vegetación de matorral xerófilo rara vez impone obstáculos para el vuelo de estos organismos, lo que dificulta su captura directa por medio de redes de niebla aun en los sitios en donde parece más probable hacerlo. También es posible que de manera natural no sean un grupo abundante, aunque se han observado colonias constituidas por al menos 30 animales de la especie Antrozous pallidus (obs. pers.), además la presencia de Tadarida brasiliensis (Aragón y Garza 1999; CONANP 2006) lo que permite suponer una colonia de tal tamaño o mayor. También es importante considerar que algunas de las especies son migratorias por lo que su presencia en la RBM es temporal, lo que contribuye con la baja abundancia natural.

Actualmente se cuenta con algunos detalles de la pequeña población de Antrozous pallidus que se percha en las instalaciones del Laboratorio del Desierto. Sin embargo, de manera general se carece de información para las otras especies de murciélagos, por lo que es conveniente su investigación a través de su captura directa o mediante el registro de sus sonidos con las técnicas de bioacústica para incrementar el conocimiento de estos organismos en este ecosistema desértico.

El número de fotografías en las que se registraron las liebres fue escasa, a pesar de que éstas son muy abundantes en la RBM (Delibes et al. 1986; Delibes e Hiraldo 1987; Hernández y Delibes 1994; Marín et al. 2003; Laundré et al. 2009; Hernández et al. 2011b) y se han registrado tanto en las áreas de matorral, en la falda de los cerros, en la zona de pastizal y en la de dunas. Por ello, estos registros fueron contradictorios y también contrastan con los 
de tres estudios recientes en los que se obtuvieron 747, 241 y 765 registros fotográficos de liebres respectivamente (Martínez 2005; Aguilar-Martínez 2008; Arias del Razo et al. 2012). Esto pudiera deberse a que las áreas muestreadas presentan condiciones que no favorecen una alta abundancia de liebres, como puede ser una pobre cantidad de alimento (Marín et al. 2003; Hernández et al. 2011 b) o la presencia de depredadores (Laundré et al. 2009).

Se obtuvo un bajo número de fotografías de conejos, lo que corresponde con estudios previos que registran que éstos son poco abundantes en la RBM en comparación con las liebres (Martínez 2005; Aguilar-Martínez 2008; Arias del Razo et al. 2012), y su abundancia promedio se ha estimado en matorral es de 4.14individuos/kmyen pastizal de 3.57individuos/ km que quizá esté relacionada de manera positiva con el nivel de precipitación en la zona (Grajales-Tam com. pers.).

Tanto los conejos como las liebres emplean las diferentes asociaciones vegetales de maneras distintas, por lo que en algunas zonas de las RBM éstos presentan diferencias en su abundancia entre áreas de nopaleras, pastizal, magueyal, gobernadora y la vegetación de la ladera del Cerro San Ignacio (Arroyo-Rodríguez 2005). Aunado a esto, ambos lagomorfos se registraron con mayor abundancia en determinadas áreas de la RBM, como la ladera del Cerro San Ignacio y la vegetación abundante de las zonas de matorral en comparación con la zona de dunas y el pastizal al norte de la RBM (López-Vidal et al. 2014). Así mismo, se observó que en donde estos lagomorfos ocurren, los conejos fueron registrados con mayor frecuencia en áreas con cobertura vegetal densa y la liebres en áreas de poca cobertura (Ramírez com. pers.).

Los roedores son el grupo de mamíferos con mayor diversidad de especies en la RBM, dentro de las que destacan particularmente Dipodomys merriami, D. nelsoni y Neotoma leucodon porque de ellas se obtuvieron el mayor número de fotografías, lo cual indica que éstas han sido reconocidas como dominantes o subdominantes en el área (Hernández et al. 2005; 2011a). En el caso particular de las ratas nopaleras ( $N$. leucodon) éstas eran poco abundantes entre los años de 1997 a 2001 (Hernández et al. 2005; 2011a), su número se ha incrementado recientemente y actualmente son muy abundantes en las áreas de matorral y pastizal de la RBM. Esta situación está directamente relacionada con las condiciones ambientales, en particular los niveles de precipitación, que ha favorecido el incremento poblacional de estos organismos cuando el nivel de lluvia es alto y hay abundante de alimento (Hernández et al. 2005 y 2011 a).

Las ardillas, de manera similar a los conejos, se registraron con una baja frecuencia en las fotografías, lo que corresponde con las observaciones de estudios previos que indican que éstas son poco abundantes en la Reserva (Serrano 1987; Hernández et al. 2005 y 2011 a) aunque presentan distribución agregada en algunas zonas (Aragón et al. 1993). Estos roedores se registraron en cada uno de los sitios muestreados, tanto en la época seca como en la húmeda, las cuales incluyeron la temporada de actividad de las ardillas, considerando que éstas presentan un periodo de hibernación que ocurre de diciembre a febrero, cuando la temperatura ambiental es menor de $15^{\circ} \mathrm{C}$ (Aragón et al. 1993).

En conclusión, el presente estudio demuestra que a través de las cámaras trampa y las cámaras de uso manual pueden reconocerse con certeza las diferentes características de las especies que permiten su correcta identidad taxonómica siempre y cuando la posición e iluminación del organismo sea la correcta para ello. Las especies pequeñas en general no es posible identificarlas adecuadamente mediante cámaras trampa, por lo que forzosamente 
deben capturarse para realizar observaciones directas y obtener imágenes con cámaras manuales. El registro fotográfico a través de las cámaras trampa, junto con observaciones directas permitió conocer algunas de las actividades de varias de las especies que habitan en la Reserva de la Biosfera de Mapimí.

Es importante destacar que el presente escrito es un esfuerzo conjunto de diferentes investigadores que han llevado a cabo variados estudios de manera independiente en la RBM a lo largo de casi 20 años y como parte de sus resultados han adquirido valiosos acervos fotográficos que se han reunido en este manuscrito. La documentación de las especies de mamíferos a través de imágenes fotográficas aporta información relacionada con diferentes aspectos de su biología que no habían sido abordados anteriormente con este método en esta localidad. Al mismo tiempo proporcionaron información actualizada de varias especies que permitió reconocer los vacíos de conocimiento que aún persisten para algunas de ellas y sobre los cuales pueden dirigirse numerosos esfuerzos de investigación, lo que sin duda contribuye a la comprensión de la dinámica de la comunidad de mamíferos que habitan en el Desierto Chihuahuense.

Este manuscrito está dedicado especialmente a la memoria de L. Hernández García, quien fue pionera en el estudio de los mamíferos en la Reserva de la Biosfera de Mapimí y que de manera muy entusiasta nos invitó a participar con ella en esta tarea. Este escrito es solo un pequeño fruto del trabajo que realizamos en conjunto y que con gusto continuaremos. Fue muy grato trabajar con ella y afortunadamente aún tuvimos la oportunidad de contar con sus comentarios para la elaboración de este documento. Te extrañamos. Los autores desean agradecer a los numerosos estudiantes de Biología de la Escuela Nacional de Ciencias Biológicas del Instituto Politécnico Nacional que colaboraron con entusiasmo para obtener las imágenes del presente estudio. Se agradece especialmente a K. Grajales-Tam, L. Díaz, E. Rodríguez, A. Guerra y a A. y F. Herrera por el apoyo brindado a lo largo de las diferentes etapas de este estudio. Al Consejo Nacional de Ciencia y Tecnología (CONACyT) por haber otorgado las becas de posgrado a CEA (167852) y JCLV (167853). Al Consejo Nacional de Ciencia y Tecnología del estado de Durango (COCyTED) por el apoyo financiero otorgado a través del proyecto DGO-2006-C01-4383 a LH. Al Posgrado en Ciencias Biológicas de la UNAM y al Doctorado en Ciencias Biológicas y de la Salud de la UAM unidad Xochimilco, por la formación académica recibida. A la Escuela Nacional de Ciencias Biológicas del Instituto Politécnico Nacional por otorgar permisos y facilidades para la realización de los proyectos mencionados. Al Instituto de Ecología A. C. por facilitar el acceso y uso de las instalaciones del laboratorio del desierto. A CONABIO por otorgar el financiamiento para la realización del presente estudio a través del proyecto GT022 a cargo de CEA, este manuscrito forma parte de los resultados del mismo. A la SEMARNAT por otorgar los permisos para la realización de los proyectos mencionados y al personal de CONANP por brindar todas las facilidades durante el estudio. También deseamos agradecer los comentarios de dos revisores anónimos cuyos comentarios enriquecieron significativamente el presente manuscrito. 
Aguilar-Martínez, G. F. 2008. Efecto del riesgo de la depredación en la selección del hábitat para el conejo cola de algodón (Sylvilagus audubonii) y la liebre de cola negra (Lepus californicus). Tesis Licenciatura, Escuela Nacional de Ciencias Biológicas, Instituto Politécnico Nacional. Ciudad de México, México.

Aragón, E., N. Millán, y C. Baudoin. 1993. Ciclos de actividad y organización espacial de las ardillas Spermophilus spilosoma y S. mexicanus (Rodentia: Sciuridae) en el desierto Chihuahuense, Durango, México. Pp. 273-287 en Avances en el Estudio de los Mamíferos de México. Publicaciones Especiales I. Asociación Mexicana de Mastozoologia A. C. Ciudad de México, México.

Aragón, P. E. E., y A. Garza H. 1999. Actualización del inventario de los mamíferos silvestres de la Reserva de la Biosfera de Mapimí. Acta Científica Potosina 14:7-25.

Arias Del Razo, I., L. Hernández, J. W. Laundré, y L. Velasco-Vázquez. 2012. The landscape of fear: habitat use by a predator (Canis latrans) and its main prey (Lepus californicus and Sylvilagus audubonii). Canadian Journal of Zoology 90:683-693.

Arroyo-Rodríguez, V. 2005. Uso de diferentes asociaciones vegetales por lagomorfos en Mapimí, Durango, México. Acta Zoológica Mexicana (n. s.) 21:151-153.

Bárcenas, V. H., y R. A. Medellín. 2007. Registros notables de mamíferos en el sur del Distrito Federal. Revista Mexicana de Mastozoología 11:73-79.

Ceballos, G., y J. Arrovo-Cabrales. 2012. Lista actualizada de los mamíferos de México. Revista Mexicana de Mastozoología Nueva Época 2:27-80.

Cecaira-Ricoy, R., J. A. Iglesias-Hernández, J. F. Charré-Medellín, R. Bolaños-Martínez, G. E. Magaña-Cota, V. Sánchez-Cordero, E. Kato Miranda, y F. J. Botello L. 2012. Registro notable de tres especies de mamíferos en la Reserva de la Biosfera Sierra Gorda de Guanajuato. Pp. 280-282 en Estudio de Estado Vol. II. México. Comisión Nacional para el Conocimiento y Uso de la Biodiversidad (CONABIO)/Instituto de Ecología del Estado de Guanajuato (IEE). Ciudad de México, México.

Charre-Medellín, J. F., V. Sánchez-Cordero, G. E. Magaña-Cota, y F. J. Botello L. 2012. Estudio de la diversidad de mamíferos de talla mediana y grande del municipio de Victoria. Pp. 277-279 en La Biodiversidad de Guanajuato. Estudio de Estado Vol. II. México. Comisión Nacional para el Conocimiento y Uso de la Biodiversidad (CONABIO)/Instituto de Ecología del Estado de Guanajuato (IEE). Ciudad de México, México.

Chávez-León, G. 2005. A recent record of Leopardus pardalis (Linnaeus, 1758) from Michoacán, México. Revista Mexicana de Mastozoología 9:122-126.

Conanp (Comisión Nacional Áreas Naturales Protegidas). 2006. Programa de Conservación y Manejo de la Reserva de la Biosfera de Mapimí, México. Comisión Nacional de Áreas Naturales Protegidas. Ciudad de México, México.

Cornet, A. 1988. Principales caractéristiques climatiques. Pp. 45-76 en Estudio integrado de los recursos vegetación, suelo y agua en la Reserva de la Biosfera de Mapimíl. Ambiente natural y humano. C. Montaña Ed. Instituto de Ecología A. C. Ciudad de México, México.

CutLer, T. L., y D. E. Swan. 1999. Using remote photography in wildlife ecology: a review. Wildlife Society Bulletin 27:571-581.

Delibes, M., L. Hernández, y F. Hiraldo. 1986. Datos preliminares sobre la ecología del coyote y gato montés en el sur del Desierto de Chihuahua, México. Historia Natural 6:77-82. 
Delibes, M., y F. HiRaldo. 1987. Food habits of the bobcat in two habitats of the southwestern Chihuahuan desert. The Southwestern Naturalist 32:457-461.

Elizalde-Arellano, C. 2012. Demanda energética y mecanismos de coexistencia de linces (Lynx rufus) y coyotes (Canis latrans) en la Reserva de la Biosfera de Mapimí, México. Tesis de Doctorado, Universidad Autónoma Metropolitana, Unidad Xochimilco. Ciudad de México, México.

Elizalde-Arellano, C., López-Vidal J. C., L. Hernández, J. W. Laundré, F. A. Cervantes, y M. Alonso-Spilsbury. 2012. Home range size and activity pattern of bobcats (Lynx rufus) in the southern part of their range in the Chihuahuan Desert, Mexico. American Midland Naturalist 168:247-264.

Esparza-Carlos, J. P., J. W. Laundré, y V. J. Sosa. 2011. Precipitation impacts on mule deer habitat use in the Chihuahuan desert of Mexico. Journal of Arid Environments 75:1008-1015.

Faller-Menéndez, J. C., T. Urquiza-Haas, C. Chávez, S. Johnson, y G. Ceballos. 2005. Registros de mamíferos en la reserva privada El Zapotal, en el noreste de la península de Yucatán. Revista Mexicana de Mastozoología 9:127-139.

Faller-Menéndez, J. C., L. A. Lago-Torres, A. Hernández-Cardona, M. Calleja-Alvarado, G. Ceballos, C. Chávez, y S. Johnson. 2007. La video-filmación como técnica de estudio de mamíferos silvestres: un ejemplo de jaguares en el noreste de la península de Yucatán. Revista Mexicana de Mastozoología 11:47-56.

Hernández, L., y M. Delibes. 1985. Alimentación de Vulpes macrotis (Merriam, 1888) en dos desiertos de México. Octavo Congreso Nacional de Zoología, Escuela Superior del Estado de Coahuila. Saltillo, México.

Hernández, L., F. Pizarro, y M. Delibes. 1989. Dietas del coyote (Canis latrans) y zorra gris (Urocyon cinereoargenteus) en la Reserva del a Biosfera de Mapimí. Sexto Simposio sobre Fauna Silvestre, Facultad de Medicina Veterinaria y Zootecnia, Universidad Nacional Autónoma de México. Ciudad de México, México.

Hernández, L. M. Delibes, y E. Escurra. 1993. Activity pattern, home range and habitat preference by coyotes (Canis latrans) in the Mapimí Biosphere Reserve of the Chihuahuan Desert, Mexico. Doñana Acta Vertebrata 20:276-283.

Hernández, L., y M. Delibes. 1994. Seasonal food habits of coyotes, Canis latrans, in the Bolsón de Mapimí, Southern Chihuahuan Desert, Mexico. Z. Söugertierkunde 59:82-86.

Hernández, L. M. Delibes, y F. Hiraldo. 1994. Role of reptiles and arthropods in the diet of the coyotes in extreme desert areas of northern Mexico. Journal of Arid Environments 26:165-170.

Hernández, L., A. G. Romero, J. W. Laundré, D. Lightfoot, E. Aragón, y J. L. Portillo. 2005. Changes in rodent community structure in the Chihuahuan desert Mexico: comparisons between two habitats. Journal of Arid Environments 60:239-257.

Hernández, L., J. W. Laundré, A. González-Romero, J. López-Portillo, y K. M. Grajales. 2011 a. Tale of two metrics: density and biomass in a desert rodent community. Journal of Mammalogy 92:840-851.

Hernández, L. J. W. Laundré, K. M. Grajales, G. L. Portales, J. López-Portillo, A. GonzálezRomero, A. García, y J. M. Martinez. 2011b. Plant productivity, predation and the abundance of black-tailed jackrabbits in the Chihuahuan desert of Mexico. Journal of Arid Environments 75:1043-1049. 
Iglesias-Hernández, J. A., V. Sánchez-Cordero, G. E. Magaña-Cota, R. Bolaños M., y F. J. Botello L. 2012. Diversidad de mamíferos medianos y grandes en el municipio de Xichú. Pp. 275-276 en La Biodiversidad de Guanajuato, Estudio de Estado Vol. II. México. Comisión Nacional para el Conocimiento y Uso de la Biodiversidad (CONABIO)/ Instituto de Ecología del Estado de Guanajuato (IEE). Ciudad de México, México.

Jiménez-Maldonado, R. E., y C. López-GonzÁlez. 2011. La tuza real (Agoutipaca), nueva especie para la mastofauna del estado de Querétaro, México. Therya 2:285-288.

Kelly, M. J., A. J. Noss, M. S. Di Bettiti, L. Maffei, R. L. Arispe, A. Paviolo, C. D. De Angelo, y E. DI BLANCo. 2008. Estimating puma densities from camera trapping across three study sites: Bolivia, Argentina and Belize. Journal of Mammalogy 89:408-418.

Laundré, J. W., J. M. Martínez, y L. Hernández. 2009. Foraging in the landscape of fear, the predator's dilemma: where should I hunt? The Open Ecology Journal 2:1-6.

Lyra-Jorge, M. A., G. Ciochetı, V. R. Pivello, y S. T. Mirelles. 2008. Comparing methods for sampling large and medium size mammals: camera traps and track plots. European Journal of Wildlife Research 54:739-744.

López-VIDAL, J. C. 2014. El paisaje del miedo y el uso del hábitat por el gato montés (Lynx rufus) en el desierto Chihuahuense. Tesis Doctorado, Universidad Nacional Autónoma de México. Ciudad de México, México.

López-Vidal, J.C., C. Elizalde-Arellano C., L. Hernández, J. W. Laundré, A. González y F. A. Cervantes. 2014. Foraging of the bobcat (Lynx rufus) in the Chihuahuan Desert: generalist or specialist? The Southwestern Naturalist.

Marín, A. I., L. Hernández, y J. W. Laundré. 2003. Predation risk and food quantity in the selection of habitat by black-tailed jackrabbit (Lepus californicus): an optimal foraging approach. Journal of Arid Environments 55:101-110.

Martínez, C. J. M. 2005. Forrajeo óptimo del coyote en la Reserva de la Biosfera de Mapimí. Tesis de Licenciatura, Universidad Autónoma de Ciudad Juárez. Ciudad Juárez, México.

Maury, M. E. 1992. El medio vegetal. Pp. 65-69 en Actas del Seminario Mapimí. Estudio de las relaciones agua-suelo-vegetación en una zona árida del Norte de México orientado a la utilización nacional de estos recursos para la ganadería extensiva de bovinos. Gómez Palacio, Durango, México 23-29 de Octubre de 1989. Instituto de Ecología A. C., Institut Francais de Recherche Scientifique pour le Development en Cooperation (ORSTOM). Centro de Estudios Mexicanos y Centro Americanos. Ciudad de México, México.

Montaña, C. 1988. Las formaciones vegetales. Pp. 167-197 en Estudio integrado de los recursos vegetación, suelo y agua en la Reserva de la Biosfera de Mapimí. I. Ambiente natural y humano (Montaña C., ed.). Instituto de Ecología A. C. Ciudad de México, México.

Pérez, C. S., y E. S. Matus P. 2010. El tapir, Tapirus bairdii, en la región sureste del área de protección de Flora y Fauna Bala'an Ka'ax, Quintana Roo, México. Therya 1:137-144.

Ramírez Bravo, O. E. 2011. New records of tayra (Eira Barbara Linnaeus 1758) in Puebla. Central Mexico. Acta Zoológica Mexicana 27:883-886.

Ramírez Silva, J. P. 2000. Composición de la dieta del pecarí de collar (Pecari tajacu) en la Reserva de la Biosfera de Mapimí, Durango. Tesis de Licenciatura, Escuela Nacional de Estudios Superiores - Iztacala, Universidad Nacional Autónoma de México. Ciudad de México, México. 
Sánchez, O., C. Elizalde-Arellano, J. C. López-Vidal, G. Magaña-Cota, G. Téllez-Girón, F. Botello, y V. Sánchez-Cordero. 2012. Mamíferos Silvestres. Pp. 263-274 en La Biodiversidad de Guanajuato, Estudio de Estado Vol. II. México. Comisión Nacional para el Conocimiento y Uso de la Biodiversidad (CONABIO)/Instituto de Ecología del Estado de Guanajuato (IEE). Ciudad de México, México.

Sánchez-Rojas, G., y S. Gallina. 2000a. Factors affecting habitat use by mule deer (Odocoileus hemionus) in the central part of the Chihuahuan Desert, Mexico: an assessment with univariate and multivariate methods. Ethology, Ecology and Evolution 12:405-417.

Sánchez-Rojas, G., y S. Galuina. 2000b. Mule deer (Odocoileus hemionus) density in a landscape element of the Chihuahuan Desert, Mexico. Journal of Arid Environments 44:357-368.

Sbrek-Araujo, A. C., y A. Garcia Ch. 2005. Is camera-trapping an efficient method for surveying mammals in Neotropical Forests? A case study in South-eastern Brazil. Journal of Tropical Ecology 21:121-125.

Serrano, V. 1987. Las comunidades de roedores desertícolas del bolsón de Mapimí, Durango. Acta Zoológica Mexicana (n. s.) 20:1-22.

Sikes, R. S., W. L. Gannon, y The Animal Care and Use Comittee of the American Society of Mammalogists. 2011. Guidelines of the American Society of Mammalogist for the use of wild mammals in research. Journal of Mammalogy 92:235-253.

Silveira, L., A. T. A. JÁcomo, y J. A. F. Diniz-Filno. 2003. Camera trap, line transect census and track surveys: a comparative evaluation. Biological Conservation 114:351-355.

SMITH, R. J., Y J. S. BRown. 1991. A practical technique for measuring the behavior of foraging animals. The American Biology Teacher 52:236-242.

Sunquist, M., y F. Sunquist. 2002. Wild cats of the world. The University of Chicago Press. Chicago, EE.UU.

Trolle, M., Y M. Kerr. 2005. Camera trap study of ocelot and other secretive mammals in the northern Pantanal. Mammalia 69:405-412.

Vaughan, T. A., J. M. Ryan, y N. J. Czaplewsky. 2011. Mammalogy. Jones and Bartlett Publishers. Sudbury, EE.UU.

Villa, R. B., y F. A. Cervantes. 2003. Los mamíferos de México. Editorial Iberoamérica, S. A. de C. V. e Instituto de Biología U.N.A.M. Ciudad de México. México.

Wemmer C., T. H. Kunz, G. Lundie-Jenkins y W. J. McShea. 1996. Mammalian Sign. Pp. 157-176 en Measuring and monitoring biological diversity, Standard Methods for Mammals. (Wilson, D. E., F. Russell C., J. D. Nichols, R. Rudran, y M. S. Foster, eds.). Smithsonian Institution. Washington, EE. UU.

Sometido: 11 de noviembre de 2014

Revisado: 5 de diciembre de 2014

Aceptado: 19 de diciembre de 2014

Editor asociado: Consuelo Lorenzo 